\title{
PARTICIPAÇÃO DOS APOSENTADOS NO MERCADO DE TRABALHO: UMA ANÁLISE COMPARADA ENTRE OS ESTADOS DA REGIÃO SUDESTE, BRASIL
}

\author{
M. C. BARRETO ${ }^{1}$, T. DE M. T. DA COSTA ${ }^{2}$, R. A. BASTOS FILHO ${ }^{3}$, L. DE P. MORAES ${ }^{4}$ \\ Universidade Federal de Viçosa ${ }^{1,2,4}$, Universidade do Estado de Minas Gerais ${ }^{3}$ \\ maiara.barreto@ufv.br ${ }^{1}$
}

Submetido 05/02/2020 - Aceito 18/03/2020

DOI: $10.15628 /$ holos.2020.9505

\section{RESUMO}

A proposta deste estudo é conhecer o perfil do aposentado da região Sudeste que continua no mercado de trabalho após se aposentar. Discutiu-se sobre a (re)inserção dos idosos no mercado de trabalho e o pacto intergeracional da previdência social brasileira. Através de testes estatísticos, como o Teste de Pearson $\left(x^{2}\right)$ e análise descritiva, verificou-se que o estado com mais aposentados no mercado de trabalho é São Paulo (SP); com média de renda da aposentadoria menor que a média da renda extra; o nível de instrução predominante foi o ensino fundamental incompleto; e o estado que possui maior média de rendimento extra e maior percentual de informalidade foi o Rio de Janeiro $(R J)$, sendo que uma grande parte dos aposentados que retornam ao mercado de trabalho é referência na unidade domiciliar. Tais resultados revelam que a associação corrente entre a velhice e aposentadoria vai perdendo espaço no imaginário social, pois nem todos os aposentados são velhos e nem toda velhice é aposentada. Assim, taís dados podem auxiliar na formulação de políticas públicas para o idoso, na previdência social, e políticas para o mercado de trabalho e saúde.

PALAVRAS-CHAVE: Aposentado, Mercado de trabalho, Políticas Públicas.

\section{PARTICIPATION OF THE RETIRED IN LABOR MARKET: A COMPARED ANALYSIS BETWEEN THE STATES OF THE SOUTHEAST REGION, BRAZIL}

\begin{abstract}
The purpose of this study is to know the profile of the retiree of the Southeast region that continues in the job market after retiring. The reintegration / insertion of the elderly in the labor market and the intergenerational pact of the Brazilian social security were discussed. Through statistical tests, such as Pearson's Test $\left(x^{2}\right)$ and descriptive analysis, it was found that the state with the most retirees in the labor market is São Paulo (SP); with average retirement income lower than extra average
\end{abstract}

income; the predominant level of education was incomplete elementary school; and the state with the extra highest average income and the highest percentage of informality was Rio de Janeiro (RJ), and a large proportion of retirees returning to the labor market are reference in the home unit. This information can influence the formulation of public policies for the elderly, social security, and policies for the labor market and health.

KEYWORDS: Retired, Job market, Public policy. 


\section{INTRODUÇÃO}

O fenômeno da longevidade está acontecendo paralelamente ao recuo da taxa de natalidade, e essa transição ocasiona a inversão da pirâmide etária no Brasil. De fato, as modificações ocorridas na estrutura etária brasileira, nas últimas décadas, causaram o estreitamento da base da sua pirâmide, configurando uma população com uma menor proporção de jovens em relação à população total e, consequentemente uma maior proporção de adultos e idosos (OBST, 2017). De acordo com o IBGE (2017), as perspectivas são de que essa inversão seja cada vez maior, chegando em 2050 com o topo da pirâmide - de idosos - alcançando perto de $30 \%$ da população.

Entretanto, o aumento da perspectiva de vida está acompanhado da permanência dos trabalhadores por mais tempo no mercado de trabalho, induzido pelo aumento da idade mínima para a aposentadoria, pelo objetivo de complemento de renda (LANCMAN; SZNELWAR; JARDIM, 2006), e outros fatores psicossociais (KHOURY et al, 2010). No Brasil, cerca de $22,5 \%$ das pessoas com 65 anos ou mais continuam trabalhando, sendo que a grande maioria $(74,7 \%)$ já é aposentada (IBGE, 2008).

Vários fatores são apontados pela literatura como sendo justificativa da permanência ou da reinserção dos idosos aposentados ao mercado de trabalho. Algumas dessas razões são: prazer pelo trabalho, ocupação do tempo livre, continuidade pelo exercício de uma atividade física e mental, além das necessidades financeiras, seja pela perda do poder aquisitivo, devido aos baixos valores dos benefícios concedidos, seja pela necessidade de prover a família (BULLA \& KAEFER, 2003).

De fato, sabe-se que existe um movimento de adiar a aposentadoria e reduzir benefícios, e as propostas de reformas da previdência estão criando limitadores para o recebimento desses, seja pela elevação da idade mínima, seja pelo tempo de contribuição dos trabalhadores. Dessa forma, tais propostas podem induzi-los a se aposentarem mais tarde visando uma compensação das perdas dos benefícios. Em contrapartida, como os brasileiros tendem a entrar cedo no mercado de trabalho, tendem também a não abrir mão de se aposentarem precocemente, convivendo, consequentemente, com a redução do valor das aposentadorias (KIEFER, 2009), sendo essa uma das causas da reinserção desse público na atividade profissional.

Como consequência, a representação do idoso inativo vem sendo substituída pela figura dos idosos dinâmicos, contribuintes do orçamento doméstico e por vezes, o representante econômico no grupo familiar (MOTTA, 2000). Cumpre destacar que o regime de financiamento da previdência social utilizado atualmente no Brasil é o de repartição simples. Neste regime os segurados contribuem, em regra, para um fundo único, responsável pelo pagamento de todos os beneficiários do sistema. Nessa estrutura ocorre o pacto intergeracional, isto é, os contribuintes de hoje custeiam os beneficiários atuais. 
Dessa forma, uma das questões que surgem diante desse cenário é: a partir desse regime de repartição simples, qual a influência da inversão da pirâmide etária ${ }^{1}$, uma vez que presenciase um aumento no número de idosos que dependem de um número menor de jovens, para a manutenção de seus benefícios, visto que tal regime é extremamente influenciado pelas taxas de natalidade do país e pela expectativa de vida de seus componentes? Entretanto, sabe-se que as premissas baseadas para seu funcionamento são relacionadas aos aspectos sociais, econômicos e etários. Não obstante, as alterações dessas premissas podem desdobrar-se em falta de equilíbrio financeiro ou atuarial.

A literatura estrangeira tem abordado a atividade remunerada após a aposentadoria como bridge employment (emprego de ponte) com foco na qualidade de vida na aposentadoria. De fato, novas formas de adequação do mercado de trabalho tendem a surgir haja vista a perspectiva futura de aposentadorias mais distantes. A União Europeia, por exemplo, desenvolve a aposentadoria parcial através da recomendação 82/857/CEE, desde 10 de dezembro de 1982, com diretrizes que orientam os Estados membros a buscarem uma transição das pessoas para a inatividade. A aposentadoria parcial pode cumprir papel relevante como mecanismo de adaptação para a inatividade, e também como adequação à natural restrição física da idade avançada (IBRAHIM, 2018).

Assim sendo, conhecer os idosos que se (re)inserem no mercado de trabalho, é fundamental para as políticas públicas, que devem agir com intervenções direcionadas à saúde, ao mercado de trabalho, bem como ações efetivas de proteção social, garantindo uma boa qualidade de vida na terceira idade para a nova perspectiva de idosos - os dinâmicos.

Diante do exposto, esse trabalho apresenta o seguinte problema de pesquisa: qual o perfil do aposentado que permanece no mercado de trabalho na região sudeste do Brasil? Para responder tal pergunta esse estudo objetivou analisar o perfil do aposentado, da região sudeste, que continua no mercado de trabalho mesmo após a sua aposentação. A pesquisa se justificativa por dois motivos principais, o primeiro que diz respeito à inversão rápida da pirâmide etária no Brasil e o segundo devido ao fato de que o Sudeste é a segunda região brasileira com maior número de aposentados, possuindo assim, uma população significativa em relação ao Brasil.

Este artigo divide-se em 5 seções, sendo a primeira essa introdução. Na segunda seção, é apresentada a revisão de literatura, destacando a previdência social como política pública e o seu pacto intergeracional. Na terceira seção, são abordados os procedimentos metodológicos para cumprimento do objetivo. Na quarta, são analisados os resultados e discussões. Por fim, na quinta seção, são apresentadas as considerações finais do estudo. Espera-se desse trabalho uma contribuição para a literatura acerca da permanência dos idosos no mercado de trabalho, bem como facilitar o direcionamento das políticas públicas decorrentes desse fenômeno social.

\footnotetext{
${ }^{1}$ A inversão da pirâmide etária é uma das situações que ocorrem e que podem afetar o sistema previdenciário pautado na repartição simples. Contudo existem outros problemas no Brasil que também implicam no funcionamento da previdência como improbidades, desvios de recursos para fins não previdenciários através da DRU - Desvinculação de Receitas da União, entre outros.
} 


\section{REVISÃO DE LITERATURA}

2.1 A (re)inserção dos idosos aposentados no mercado de trabalho e o pacto intergeracional da previdência social brasileira

As políticas públicas buscam proporcionar mais bem-estar, desenvolvimento, justiça social, maior coesão, através dos instrumentos operacionais das políticas públicas que são as leis, as regulamentações, os incentivos fiscais e os programas. O programa público é formado por ações planejadas, sistêmicas e articuladas entre si, com o objetivo de atender uma demanda pública específica. Para tanto é necessário determinar seus objetivos de forma clara, o modelo de intervenção delineado para abordar o problema social e o público a ser atingido (JANNUZZI, 2016).

A previdência social enquanto política pública busca amparar o trabalhador e proporcionar desenvolvimento socioeconômico no país, principalmente quando considerado as aposentadorias e benefícios em geral, pois representam grande relevância na estabilidade social do Brasil. Desse modo, a interferência do Estado na economia através de políticas públicas e programas fundamenta-se pela busca de equidade e eficiência propositando melhores indicadores sociais, refletido pelo melhor nível de bem-estar e de renda (CAVALIERI; PAZELLO, 2005).

O sistema previdenciário atual pode ser dividido em três componentes: Regime Geral de Previdência Social (RGPS), administrado pelo Instituto Nacional do Seguro Social (INSS); Regime Próprio de Previdência Social (RPPS) da União, estados, municípios e Distrito Federal, englobando de forma compulsória todos os servidores públicos efetivos desses entes públicos; e Regime de Previdência Complementar, do qual fazem partes as Entidades Abertas e as Fechadas de Previdência Complementar (TURRA, AFONSO, 2017).

De fato, a Previdência Social tem papel central para a sociedade brasileira, principalmente a partir da expansão dos benefícios ocorrida com a CF/88, com o envelhecimento populacional, o lento crescimento econômico entre outras mudanças vivenciadas no cenário nacional, incluindo também a sua importância como mecanismo de distribuição de renda e garantia de bem-estar para os beneficiários (TURRA, AFONSO, 2017).

No Brasil, a CF/88 consolidou um modelo centrado no sistema previdenciário como a principal - muitas vezes única - fonte de renda para o consumo em idades avançadas. Pesquisas como a de Turra (2000), Lee e Mason (2011) demonstraram que o padrão brasileiro de transferências públicas entre gerações é bastante atípico se comparado ao de países de diferentes continentes e variados níveis de renda, caracterizado por um notável viés pró-idoso. Esse viés é causado, em grande parte, pela cobertura do RGPS às idades acima de 60 anos e pelos benefícios pagos através dos regimes próprios de previdência. E pelos gastos com saúde pública, que normalmente aumentam com a idade e também contribuem para a ocorrência desse padrão (TURRA, AFONSO, 2017; ROCHA, CAETANO, 2008).

Em certos países da Ásia e América do Norte, o consumo de idosos é financiado por uma combinação de fontes de renda que vai além da Previdência Social, dando-se maior peso relativo 
às transferências na família, renda de ativos e renda no trabalho. Já no Brasil, a adoção de um modelo previdenciário centrado na principal fonte de renda para os idosos, assemelha-se ao que ocorreu em países da América do Sul, especialmente Uruguai e Argentina, e em países da Europa, que ao longo das décadas, estruturaram políticas públicas focalizadas no bem-estar social (LEE; MASON, 2011; TURRA; AFONSO, 2017).

Contudo, o benefício recebido na aposentadoria nem sempre é suficiente para manter o padrão de vida, o que gera no Brasil e também em outros países, o cenário de retorno ou permanência do aposentado ao mercado de trabalho. Todavia, isso se deve tanto por fatores psicossociais quanto por fatores financeiros (KHOURY et al, 2010). A literatura estrangeira enxerga o 'emprego de ponte' como uma alternativa para a qualidade de vida dos idosos, sendo um mecanismo de adaptação para a inatividade. Considerando o aumento da perspectiva de vida das pessoas, é natural que novas formas de adequação ao mercado de trabalha surjam (IBRAHIM, 2018). Nesta perspectiva, não somente o mercado de trabalho necessita de adequação, mas também a administração pública, que deverá analisar se as suas políticas públicas estão ajustadas com essa realidade.

\section{PROCEDIMENTOS METODOLÓGICOS}

Este estudo é considerado como de abordagem quantitativo devido ao fato da unidade de análise ser composta por dados estatísticos de fontes secundárias, utilizando-se de microdados da Pesquisa Nacional de Amostra por Domicílio (PNAD). Os campos de observação foram os estados brasileiros de Minas Gerais, Rio de Janeiro, Espírito Santo e São Paulo que comportam a região sudeste, com ênfase nas informações acerca dos aposentados da previdência social.

A base de dados utilizada foi o microdado da PNAD/2015, por serem os dados mais recentes. O Sudeste, em 2015 possuía 17,02\% da população aposentada trabalhando, sendo a segunda região do Brasil com maior percentual, perdendo apenas para a região Sul com 21,75\% de aposentados em atividade profissional.

Para este estudo foram coletadas as seguintes variáveis: atividade e inatividade dos aposentados, idade média, cor/raça, aposentadoria média, renda média extra, escolaridade, local de moradia (rural ou urbano), formalidade e informalidade do trabalho. Utilizou-se o Sistema de Informação Geográfica - SIG, com o auxílio do software $\mathrm{QGIS}^{\circledR}$, do qual foi realizado o mapeamento do percentual válido de aposentados no mercado de trabalho na região sudeste brasileira, com o objetivo de contribuir para a visualização dos resultados.

Em busca de auxiliar na identificação das associações entre as variáveis, empregou-se o Teste qui-quadrado de Pearson $\left(\mathrm{x}^{2}\right)$, tendo em vista que as variáveis coletadas são nominais e não seguem a distribuição normal (não-paramétricos). O nível de significância adotado é de 5\% $(0,05)$, de modo a identificar se existe ou não associação entre duas variáveis. Os dados foram analisados, estatisticamente, com o auxílio do software SPSS ${ }^{\circledR}$ (Statistical Package for the Social Sciences), extraindo o teste de normalidade, a estatística descritiva e teste qui-quadrado. 


\section{RESULTADOS E DISCUSSÕES}

Inicialmente são apresentados os resultados com informações acerca do perfil dos aposentados que retornam ao mercado de trabalho abordando quantidade de aposentados no mercado de trabalho por estado; média de idade; sexo; média da renda; escolaridade; pessoa de referência na unidade domiciliar e formalidade do trabalho, trazendo informações gerais. Posteriormente as informações são apontadas de forma detalhada por estado.

\subsection{Perfil dos aposentados que retornam ao mercado de trabalho}

Em relação à quantidade de aposentados no mercado de trabalho em cada estado, a análise descritiva permitiu identificar que o estado de São Paulo (SP) possui o maior percentual válido (38,3\%), estando Minas Gerais (MG) com o segundo maior percentual (37,5\%), Rio de Janeiro (RJ) $(19,2 \%)$ e Espírito Santo (ES) (5\%) respectivamente. Utilizou-se todos indivíduos, ou seja, a população de aposentados no mercado de trabalho, descritos no PNAD (2015), totalizando 2107 indivíduos. Conforme exposto na Figura 1, abaixo, é possível visualizar através do mapa dos Estados da Região Sudeste, os percentuais válidos de aposentados atuantes no mercado de trabalho.

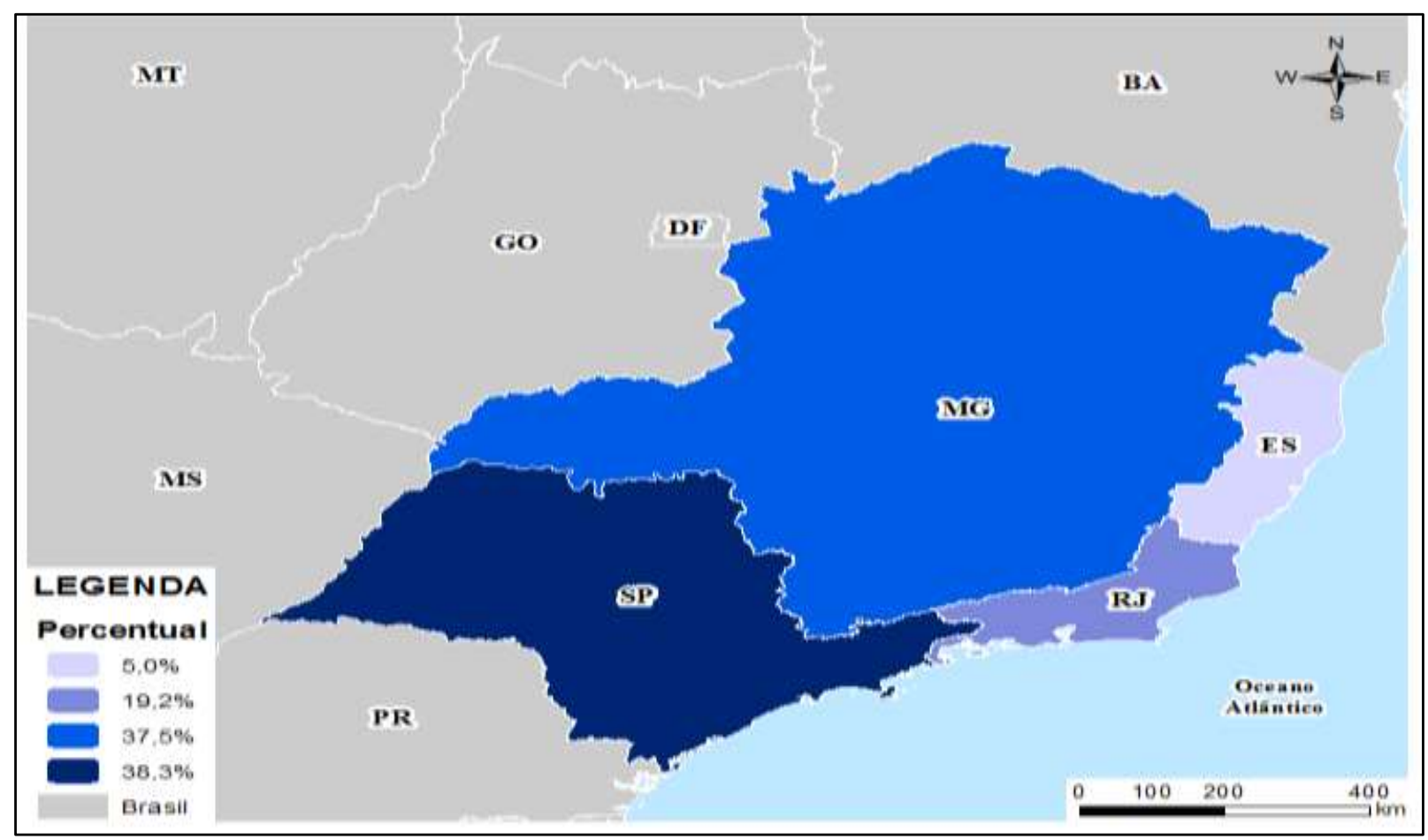

Figura 1 - Percentual válido de aposentados no mercado de trabalho na região Sudeste brasileira em 2015. Fonte: Elaborado pelos autores com auxílio do software QGIS.

$\mathrm{Na}$ amostra total, a média de idade dos aposentados no mercado de trabalho foi de 64 anos $(\sigma=7,502)$; estes possuem aproximadamente 9 anos de estudo $(\sigma=5,032)$, ou seja, variando entre o ensino fundamental e o ensino médio. A média da renda da aposentadoria foi de 
$\mathrm{R} \$ 1619,60$ ( $\sigma=1723,754)$, enquanto que a média da renda do trabalho extra foi de $\mathrm{R} \$ 2675,17$ ( $\sigma$ $=4747,511)$.

Observando que a média da renda da aposentadoria é menor que a média da renda extra. Infere-se dessa forma que nesta população, a renda pode ter sido um fator contribuinte para o retorno desses aposentados ao mercado, mas não se pode afirmar que foi o fator determinante, conforme já documentado nos trabalhos de Vanzella, Neto; Silva (2001); Bulla; Kaefer (2003).

Sabe-se que existem outros fatores que contribuem para essa decisão que não são mensurados nesta pesquisa, como apresentando por Khoury et al (2010), onde concluiu que a necessidade de se sentir produtivo é uma das principais razões para o retorno do aposentado ao mercado de trabalho, considerando assim a importância do trabalho para a constituição da identidade. Contudo, também há outros estudos que enfatizam a renda como um fator significativo para essa decisão, como observado por Camarano (2001). Todavia, para afirmar é necessário que haja um estudo mais aprofundado com análise de outras variáveis (além das que foram mensuradas nesse trabalho) que permitam realizar tal inferência.

Um percentual significativo desses aposentados são pessoas de referência ${ }^{2}$ na unidade domiciliar (percentual válido=74,7\%). Essa observação também foi realizada por Camarano (2001) que analisou a participação do idoso brasileiro nas atividades econômicas entre 1978 e 1998. Seu estudo mostrou que mais da metade dos idosos do sexo masculino e quase $1 / 3$ do sexo feminino que estavam no mercado de trabalho eram aposentados em 1998. Pode concluir também que a renda do trabalho desses aposentados tem um peso bastante significativo na sua renda e na de suas famílias, podendo a sua participação no mercado ser um indicador de sua dependência.

Mesmo o estudo de Camarano (2001) sendo realizado em época distinta, nota-se que o cenário atual permanece similar, sofrendo poucas alterações. No momento em que os aposentados deveriam gozar do seu período de descanso, eles trabalham e são em grande parte os responsáveis pelas finanças da família.

De acordo com a população do presente estudo, observou-se que 59,9\% dos aposentados no mercado são brancos e o nível de instrução mais elevado que predominou foi fundamental incompleto (percentual válido=37,2\%) e superior completo (percentual válido=22\%). E os domićlios dos aposentados que trabalham estão predominantemente na área urbana $(88,6 \%)$.

Outra análise realizada, importante principalmente do ponto de vista da sustentabilidade do sistema previdenciário, diz respeito à formalidade do trabalho vivenciado pelos aposentados, do qual foi possível observar que no Sudeste, objeto de análise desse trabalho (tabela 1, abaixo), grande parte dos aposentados retorna para o mercado formalmente, ou seja, 82,5\% retornaram com carteira assinada.

Tabela 1 - Percentual válido do tipo de trabalho dos aposentados no mercado em 2015

\section{Frequência \\ Percentual Válido}

2 Pessoas de referência são consideradas pelo IBGE (2016) como o responsável pela unidade domiciliar ou pela família.

HOLOS, Ano 36, v.3, e9505, 2020 


\begin{tabular}{lll}
\hline Sem carteira & 368 & 17,5 \\
Com carteira & 1739 & 82,5 \\
\hline Total & 2107 & 100,0 \\
\hline
\end{tabular}

Fonte: dados da pesquisa (2018).

O estudo também revelou que em toda a região estudada, há predominância de homens aposentados no mercado de trabalho $(66,10 \%)$ quando comparado com mulheres $(33,9 \%)$. Fato este que revela uma masculinização nesta perspectiva de trabalho.

\subsection{Análises do perfil dos aposentados da Região Sudeste, por Estado}

O estudo revelou que a média da idade desses aposentados estão entre 63 e 64 anos e os extremos das idades entre 40 e 92 anos, conforme segue na tabela 2 a seguir. Essas análises se tornam importante, principalmente, considerando que esse fenômeno social é relativamente contemporâneo e que impactam de forma direta na previdência social brasileira e nas propostas de reforma que estão sendo discutidas de forma excessiva ultimamente, e que propõem novas idades para a concessão da aposentadoria.

Tabela 2 - Idade mínima, máxima e média da idade dos aposentados que trabalham nos estados da região sudeste em 2015

\begin{tabular}{ccccc}
\hline Estado & Idade mínima & Idade máxima & Média & Desvio Padrão \\
\hline ES & 50 & 80 & 64,89 & 6,558 \\
MG & 43 & 88 & 64,12 & 7,707 \\
RJ & 44 & 87 & 64,57 & 7,141 \\
SP & 40 & 92 & 63,25 & 7,588 \\
\hline
\end{tabular}

Fonte: dados da pesquisa (2018).

O Rio de Janeiro é o estado que possui a média do rendimento extra mais elevada quando comparada com os outros três estados do Sudeste. Fator este, importante para ser analisado, considerando que regiões metropolitanas possuem custos de vida mais elevados.

Tabela 3 - Média do rendimento do trabalho extra dos aposentados que trabalham nos estados da região sudeste em 2015

\begin{tabular}{ccc}
\hline Estado & Média & Desvio Padrão \\
\hline ES & $\mathrm{R} \$ 2431,38$ & 4616,106 \\
MG & $\mathrm{R} \$ 2344,41$ & 4978,924 \\
RJ & $\mathrm{R} \$ 3033,79$ & 5143,005 \\
SP & $\mathrm{R} \$ 2831,92$ & 4317,888 \\
\hline
\end{tabular}

Fonte: dados da pesquisa (2018).

O desvio-padrão elevado significa que os dados estão mais dispersos (PESTANA, GAGEIRO, 2008), ou seja, há uma grande discrepância entre os rendimentos extras nesta amostra. Sabe-se que a desigualdade de renda tem um impacto direto sobre o bem-estar social na medida em que as sociedades buscam a equidade (BARROS, MENDONÇA, 1995). 
A PNAD de 2015, verificou que a desigualdade social estreitou em todas as regiões do Brasil com exceção do Sudeste, do qual que não houve redução, fato que também contribuiu para os elevados desvios padrões.

Em contrapartida, a média dos rendimentos da aposentadoria foram inferiores à média dos rendimentos do trabalho extra em todos os estados analisados. Situação esta, que pode ser influenciada por diversos fenômenos como, inflação e correção das aposentadorias baixo da inflação e redução do poder de compra das aposentadorias. Essa conjuntura merece atenção e estudos aprofundados abarcando outras regiões que identifiquem os fatores que podem clarificar esse fenômeno.

Tabela 4 - Média do rendimento da aposentadoria dos aposentados que trabalham nos estados da região sudeste em 2015

\begin{tabular}{ccc}
\hline Estado & Média & Desvio Padrão \\
\hline ES & $\mathrm{R} \$ 1387,91$ & 1279,973 \\
MG & $\mathrm{R} \$ 1503,62$ & 1824,528 \\
RJ & $\mathrm{R} \$ 1794,60$ & 2147,314 \\
SP & $\mathrm{R} \$ 1620,61$ & 1343,159 \\
\hline
\end{tabular}

Fonte: dados da pesquisa (2018).

A média dos anos de estudos dos aposentados que retornaram ao mercado de trabalho na região sudeste no ano de 2015, variou entre 7 e 9 anos, ficando Espírito Santo o estado com a menor média de anos de estudos, podendo inferir que esse público tente a ocupar cargos precarizados no mercado de trabalho e que tende a ser cargos que exigem menos qualificação e consequentemente que podem não ser adequados para a idade, refletindo assim em possíveis problemas de saúde no futuro.

Tabela 5 - Média dos anos de estudo dos aposentados que retornaram ao mercado de trabalho nos estados da região sudeste no ano de 2015

\begin{tabular}{ccc}
\hline Estado & Média & Desvio Padrão \\
\hline ES & 7,29 & 5,151 \\
MG & 8,03 & 5,161 \\
RJ & 9,48 & 5,029 \\
SP & 9,64 & 4,870 \\
\hline
\end{tabular}

Fonte: dados da pesquisa (2018).

A forma como esses aposentados retornam para o mercado é um fator importante e que pode afetar no financiamento da previdência social, considerando que o sistema previdenciário brasileiro é de repartição simples, como discutido na seção "revisão de literatura". Para a variável sem carteira, o estado que obteve a frequência observada mais distante da frequência esperada foi o Rio de Janeiro e em contrapartida, a frequência observada para a variável com carteira neste mesmo estado foi abaixo da frequência esperada.

Tabela 6 - Frequência observada por Tipo de trabalho e por Estado

\begin{tabular}{ccc}
\hline Estado & Sem carteira & Com carteira \\
\hline ES & $12,26 \%$ & $87,73 \%$ \\
MG & $16,56 \%$ & $83,18 \%$ \\
RJ & $20,54 \%$ & $79,45 \%$
\end{tabular}




\begin{tabular}{ccc} 
SP & $17,49 \%$ & $82,38 \%$ \\
\hline & & 5,048 \\
P-valor & 0,168 \\
\hline
\end{tabular}

Fonte: dados da pesquisa (2018).

O nível de significância ( $p$-valor) do teste $x^{2}$ de 0,168 indica que não se pode rejeitar Ho, ou seja, as variáveis são independentes, pois o seu resultado foi maior que 0,05. Observa-se que os percentuais de aposentados no mercado de trabalho sem carteira assinada são menores que aqueles que retornam com carteira assinada. Contudo, mesmo havendo essa diferença significativa, existem informais no mercado, como também foi identificado por Cockel (2014), que identificou alto percentual de aposentados na construção civil informalmente. Seus resultados mostram que o trabalho na construção é uma necessidade familiar e que procuram obter ganhos extras indispensáveis para manter as mesmas condições financeiras anteriores à aposentadoria. Diante da baixa escolaridade de sua amostra, a construção foi uma das poucas opções restantes frente a um mercado de trabalho cada vez mais excludente.

Com relação ao nível de instrução, o estado do Espírito Santo possui maior número de aposentados que trabalham sem instrução (17,9\%), enquanto que em Minas Gerais o percentual é de $12,8 \%$, no Rio de Janeiro é $8,2 \%$ e em São Paulo é de $5,8 \%$. O percentual que mais se destacou em todos os estados foi para o nível de escolaridade ensino fundamental incompleto, sendo Minas Gerais predominante com $42,7 \%$ e o Rio de Janeiro com o menor percentual observado (32,9\%). Os estados que se destacaram no nível de escolaridade ensino superior foram Rio de Janeiro (25\%) e São Paulo (24,2\%).

Ao realizar os cruzamentos através do qui-quadrado de Pearson (Teste $x^{2}$ ), foi possível verificar se as variáveis categóricas como tipo de trabalho, cor, sexo e nível de instrução influenciaram nos padrões de respostas observados. No cruzamento entre as variáveis, situação de trabalho e cor, em busca de observar se havia relação entre a cor do aposentado e o fato dele trabalhar, foi observado que há mais brancos tanto trabalhando, quanto não trabalhando.

Tabela 7 - Tabela de referência cruzada referente à situação do trabalho e a cor do aposentado

\begin{tabular}{|c|c|c|c|}
\hline \multicolumn{2}{|c|}{ Situação de trabalho } & \multicolumn{2}{|c|}{ Cor } \\
\hline & & Não branco & Branco \\
\hline Não trabalha & Frequência observada & $43,25 \%$ & $56,75 \%$ \\
\hline \multirow[t]{3}{*}{ Trabalha } & Frequência observada & $40,05 \%$ & $59,94 \%$ \\
\hline & Qui-quadrado $\left(\chi^{2}\right)$ & 7,270 & \\
\hline & Nível de significância & 0,007 & \\
\hline
\end{tabular}

Fonte: dados da pesquisa (2018).

No cruzamento entre as variáveis, situação de trabalho e sexo, foi possível identificar que a frequência esperada por mulheres aposentadas trabalhando foi maior que a frequência observada (frequência esperada $=1002,1$; frequência observada $=714$ ) enquanto que dos homens, foi ao contrário, observou mais homens aposentados trabalhando que o esperado (frequência esperada=1104,9; frequência observada $=1393$; qui-quadrado=190,337; $p$ valor=0,000). Cockel (2014) também identificou em seu estudo maior frequência de homens aposentados que 
retornam ao mercado, todavia, por ter realizado sua pesquisa na construção civil, entende-se que é uma área mais proveniente de se encontrar homens que mulheres.

Observa-se que Camarano (2004) também identificou que os homens idosos, representam a maioria entre os chefes de família, e, esses tendem a permanecer no mercado de trabalho justamente por se considerarem a referência familiar e terem consciência da sua importância para os membros daquela família.

Ao associar situação de trabalho com nível de instrução, observou-se que o nível fundamental foi o que possuiu maior frequência para ambos os tipos de trabalho (com e sem carteira assinada). E a frequência observada ultrapassou a frequência esperada (frequência esperada $=5346,7$; frequência observada $=5438$; qui-quadrado $=219,185 ; p$ valor $=0,000$ ).

\section{CONSIDERAÇÔES FINAIS}

Esse trabalho objetivou conhecer o perfil do aposentado que continua no mercado de trabalho após se aposentar na região Sudeste por meio de uma análise comparativa entre seus estados. Observou-se que o estado com maior número de aposentados atuando no mercado de trabalho, foi São Paulo, o que se justifica por ser também o estado com maior população dentre os estados analisados. A média de idade desse público foi de 64 anos, estando os extremos entre 40 e 92 anos. Verificou-se que a média da renda da aposentadoria foi menor que a média da renda extra em todos os estados do Sudeste e que $74,7 \%$ dos idosos que estão no mercado de trabalho na região evidenciada, são referência na unidade domiciliar. O nível de instrução predominante nessa população foi o fundamental incompleto. E o estado com maior média de renda extra e maior percentual de informalidade foi o Rio de Janeiro.

Dessa forma, fica mais evidente que se vivencia a progressiva desvinculação entre o momento da aposentadoria e a última etapa da vida, denominada de terceira idade. Ou seja, a associação corrente entre a velhice e aposentadoria vai perdendo espaço no imaginário social, pois nem todos os aposentados são velhos e nem toda velhice é aposentada.

As questões relativas à previdência social no Brasil são mais amplas e consideradas um grande desafio, não sendo aprofundadas neste estudo, havendo necessidade de investigações futuras capazes de compreender os impactos sociais, econômicos e pessoais da permanência dos aposentados no mercado informal de trabalho.

A maior longevidade da população, os baixos valores das aposentadorias, o desejo de permanecer ativo, entre outros fatores apontados no decorrer do artigo, mostram novos desafios para as áreas de saúde, previdência e trabalho. Com os resultados, foi possível perceber que existem idosos optando pelo mercado informal, e mesmo que seja em percentuais baixos, é preocupante. Essa situação demanda atenção e políticas públicas específicas, bem como ações efetivas de proteção social, garantindo uma boa qualidade de vida na terceira idade.

De fato, a seguridade social representa um papel importante para a construção do bemestar dos indivíduos nesta fase da vida. Contudo, as políticas públicas para os idosos devem fomentar a solidariedade entre gerações, equilibrando as necessidades dos idosos com as 
necessidades de outros grupos populacionais. Assim, buscando a efetividade das políticas direcionadas para o envelhecimento populacional é fundamental que elas possuam uma abordagem integrada em seus setores como saúde, educação, mercado de trabalho, economia e seguridade social.

Este estudo se limitou a explorar o perfil dos aposentados que são (re)inseridos no mercado de trabalho em uma Região do Brasil, e devido a essa limitação e aos resultados obtidos torna-se oportuno propor novas pesquisas para compreender se de fato essa realidade é estendida em nível nacional, inclusive buscando compreender qual a percepção da administração pública em relação às políticas públicas que abarcam o bem estar social dos aposentados no país.

\section{REFERÊNCIAS}

BARROS, R. P. de.; MENDONÇA, R. S. P. (1995). Os determinantes da desigualdade no Brasil. In: Seminários de Pesquisa Econômica I. IPEA.

BULLA, L. C.; KAEFER, C. O. (2003). Trabalho e aposentadoria: repercussões na vida do idoso aposentado. Revista Virtual Textos e Contextos, v.2, p. 1-8, dez. Recuperado em 10 novembro, 2018, http://revistaseletronicas.pucrs.br/ojs/ index.php/fass/article/view/957.

CAMARANO, A. A.(2001). O idoso brasileiro no mercado de trabalho. Texto para discussão, no 830. Rio de Janeiro: Ipea.

CAMARANO, A. A.(2004). Os novos idosos brasileiros muito além dos 60? Rio de Janeiro: Ipea,604 p.

CAVALIERI, C. H.; PAZELLO, E. T. (2005). Efeito distributivo das políticas sociais. In: BIDERMAN, Ciro; ARVATE, Paulo (Org.). Economia do setor público no Brasil. Rio de Janeiro: Elsevier, p. 339-364.

FAVERO, L. P. L. et al. (2009). Análise de dados: modelagem multivariada para tomada de decisões. Rio de Janeiro: Elsevier.

IBGE - Instituto Brasileiro de Geografia e Estatística.(2010). Censo Demográfico. Recuperado em 15 agosto, 2017, http://www.ibge.gov.br/home/estatistica/populacao/censo2010/default.shtm

Pesquisa Nacional por Amostra de domicílios: síntese de indicadores. (2016). Rio de Janeiro: IBGE, 108 p. Recuperado em 10 de novembro, 2018, https://biblioteca.ibge.gov.br/visualizacao/livros/liv98887.pdf

- Síntese dos Indicadores Sociais: Uma análise das condições de vida da população brasileira.(2008). Recuperado em 27 de setembro, 2018, http://www.ibge.gov.br/home/estatistica/populacao/trabalhoerendimento/pnad2008/. 
IBRAHIM, F. Z. Aposentadoria parcial e bridge employment. (2018). Migalhas. Recuperado em 10 de julho, 2018, <http://www.migalhas.com.br/Previdencialhas/120,MI281560,11049Aposentadoria+parcial+e+bridge+employment>

JANNUZZI, P. M. (2016). Monitoramento e Avaliação de Programas Sociais: uma introdução aos conceitos e técnicas. Campinas: Alínea, 164 p.

KHOURY, H. T. T. et al. (2010). Porque aposentados retornam ao trabalho? O papel dos fatores psicossociais. Revista Kairós Gerontologia, São Paulo, ano 13, v. 1, p. 147-165.

KIEFER, S. Brasileiro vai trabalhar mais para garantir aposentadoria. Estado de Minas. Recuperado em 24 de agosto, 2018, http://www.uai.com.br/UAl/html/sessao_4/2009/03/24/em_noticia_interna,id_sessao=4\&i d_noticia=103721/em_noticia_interna.shtml.

LANCMAN, S., SZNELWAR, L. I., \& JARDIM, T. A.(2006). Sofrimento psíquico e envelhecimento no trabalho: um estudo com agentes de trânsito. Revista de Terapia Ocupacional da Universidade de São Paulo, 17(3), 129-136.

LEE, R. D.; MASON, A. (2011). Population aging and the generational economy: a global perspective. Northampton, MA: Edward Elgar Publishing.

MOTTA, A. B. (2000). Relações de família dos mais idosos. In: Anais do Encontro Anual da Anpocs. Petrópolis, p. 103.

PESTANA, M. H; GAGEIRO, J. N.(2008). Análise de dados para ciências sociais: a complementaridade do SPSS. 5 ed. Lisboa: Sílabo, 694 p.

ROCHA, R. R.; CAETANO, M. A. R. (2008). O Sistema Previdenciário brasileiro: uma avaliação de desempenho comparada. Textos para discussão, n. 1331. Brasília: Ipea.

TURRA, C. M.; AFONSO, L. E. (2017). A consolidação da Previdência Social desde 1988 e seu futuro em um país em envelhecimento. In: MENDES, G.; PAIVA, P. Políticas Públicas no Brasil: uma abordagem institucional. 1 ed. São Paulo: Saraiva, Cáp. 15, p. 317-350.

VANZELLA, E.; NETO, E. A. L.; SILVA, C. C. (2011). A terceira idade e o mercado de trabalho. Revista Brasileira de Ciência da Saúde, v. 14, n. 4, p. 97-100. 